\title{
Bridging the marketing theory-practice gap with marketing engineering
}

\author{
Gary L. Lilien ${ }^{\mathrm{a}, *}$, Arvind Rangaswamy ${ }^{\mathrm{a}}$, Gerrit H. van Bruggen ${ }^{\mathrm{b}}$, Berend Wierenga ${ }^{\mathrm{b}}$ \\ ${ }^{a}$ Penn State, State College, 402 BAB, University Park, PA 16802, USA \\ ${ }^{\mathrm{b}}$ Erasmus University, Rotterdam, Netherlands
}

\begin{abstract}
New developments in marketing management support systems (MMSSs) have provided the marketer with a growing supply of tools that can enrich decision making. In this paper, we describe the concept of marketing engineering — an approach to solving marketing decision problems - popularized by Lilien and Rangaswamy [Lilien GL,Rangaswamy A. Marketing engineering: computer-assisted marketing analysis and planning. Reading, MA: Addison-Wesley, 1998.]. We describe how marketing engineering harnesses marketing data and knowledge to facilitate decision making. We provide several illustrations of the successful application of the marketing engineering concept. We also summarize developments that we believe will further encourage the adoption of the marketing engineering concept and tools for both teaching about marketing decision making, and for improving the practice of marketing decision making. We conclude with some challenges for the academic research community. (C) 2001 Elsevier Science Inc. All rights reserved.
\end{abstract}

Keywords: Marketing theory-practice; Marketing engineering; Decision support

\section{Introduction}

In the past few decades, the field of marketing has evolved into a distinct academic discipline and a profession for practitioners. The field has produced many important theories and concepts (e.g., segmentation, positioning) and developed methodologies for translating them into practice (e.g., focus groups, perceptual maps). Yet, many senior managers believe that marketing is intrinsically art and experience, and is not amenable to the systematic approach to decision making that characterizes such management disciplines as finance, production, and logistics. This belief suggests that there is a gap between marketing theory and marketing practice. At the same time, the current competitive environment calls for more sophistication in making marketing decisions. It is no longer enough to justify marketing programs and expenditures purely on the basis of a "strategic rationale," or simply as "costs of doing business." Increasingly, marketing is viewed as an investment in the company's future - as a way to attract and retain profitable customers. Viewed as an investment, marketing plans have to cross the same budget justification hurdles that other investments do. 0413 .

* Corresponding author. Tel.: +1-814-863-2782; fax: +1-814-863-

E-mail address: G5L@psu.edu (G.L. Lilien).
Over the years, the marketing field has produced a number of successful decision models and decision support tools that facilitate more sophisticated thinking about marketing problems. Such models can help develop marketing strategies and plans, help anticipate the value of implementing those plans, and provide measurement frameworks for evaluating the impact of marketing plans and strategies. Yet, until recently, these models have only been available to those few managers who have been motivated to search for and locate them.

However, with the wide availability of computers and emerging user-friendly software implementations of marketing decision models, there is a growing interest among managers to use these models for both strategic and tactical decision making. A new area of marketing is emerging which helps to combine data, knowledge, managerial judgment, and computer software to facilitate decision making, which we call marketing engineering. In our view, marketing engineering is an important instrument for bridging the gap between marketing theory and practice. In this paper, we define marketing engineering, summarize the trends that favor its growth and adoption by managers, articulate the potential benefits and costs of adopting the marketing engineering approach, and illustrate a few successful applications of this concept at leading companies. While we also highlight some important research findings, we need much more research to understand "why" and "how" marketing 
engineering influences decision processes and outcomes, and to quantify the benefits that can be gained by adopting marketing engineering for addressing various marketing decision problems. We conclude with some thoughts on how the marketing engineering concept will evolve in the near future and identify several related challenges for the academic marketing community.

\section{The marketing engineering opportunity}

Marketing managers make ongoing decisions about product features, prices, distribution options, sales compensation plans, etc. In making these decisions, managers choose from among alternative courses of action in a complex and uncertain world. Like all decisions that people make, marketing decision making involves judgment calls. Most traditional marketing decision makings, while sometimes guided by the concepts and tools from our literature, have been largely based on managers' mental models, intuition, and experience.

In many cases, such mental models may be all that managers need to feel psychologically comfortable with their decisions. Yet, mental models are prone to systematic errors (Tversky and Kahneman, 1974; Russo and Schoemaker, 1989; Bazerman, 1998). While we all recognize the value of experience, that experience is unique to every person, and there is no objective way to choose between the best judgment based only on the experience of different decision makers. Experience can also be confounded with responsibility bias: sales managers might choose lower advertising budgets in favor of higher expenditures on personal selling, while advertising managers might prefer larger advertising budgets.

Consider an alternative approach to the mental model for a decision involving setting advertising expenditures: managers might choose to build a spreadsheet decision model of how the market would respond to various expenditure levels. They could then use this model to explore the sales and profit consequences of alternative expenditure levels before making a decision. The systematic translation of data and knowledge (including judgment) into a tool that is used for decision support is what we call marketing engineering. In contrast, relying solely on the mental model of the particular decision maker without using any support system is what we refer to as conceptual marketing. A third option would be to automate the decision process. For example, CoverStory (Schmitz et al., 1990) automatically analyzes scanner data. If a marketer would directly follow CoverStory's recommendations, we would call this automated marketing. Bucklin et al. (1998) foresee considerable opportunities for the computer taking over many of the traditionally human tasks associated with marketing decisions. However, given the intrinsic complexity of marketing problems (many instruments, a large number of environmental factors, including competition, and substantial un- certainty in each of these factors), we believe that for many marketing decisions, the combination of marketing support tools and the judgement of the decision maker is best. Such a combination is an important aspect of the marketing engineering approach.

More formally, we define marketing engineering as the systematic process of putting marketing data and knowledge to practical use through the planning, design, and construction of decision aids and marketing management support systems (MMSSs). Our thinking follows closely that of Wierenga and van Bruggen (1997) who provide a broad perspective on the types of MMSSs that might be developed (ranging from optimization-focused systems to creativity enhancement systems) and who argue that both the problem and the thinking/reasoning process of users determine the best system for a particular application.

There are a number of well-documented examples of successful applications of the marketing engineering concept, including the following.

$A B B$ Electric, a manufacturer and distributor of power generation equipment, wanted to increase its sales and market share in an industry that was facing a projected $50 \%$ drop in demand. By carefully analyzing and tracking customer preferences and actions, it determined which customers to focus its marketing efforts on and what features of its products were most important to those customers. It credits its ability to go from $4 \%$ market share to over $40 \%$ market share, while raising its profitability in a declining market to its marketing engineering application of choice models (Gensch et al., 1990).

Marriott was running out of good downtown locations for new full-service hotels. To maintain its growth, Marriott's management planned to locate hotels outside the downtown area that would appeal to both the business travelers and weekend leisure travelers. The company designed and developed the highly successful Courtyard by Marriott chain using the marketing engineering tool called conjoint analysis (Wind et al., 1989).

Syntex Laboratories was concerned about the productivity of its sales force. In particular, managers were unsure whether the size of the sales force was right for the job it had to do and whether the firm was allocating its sales force effort to the most profitable products and market segments. The company used a marketing engineering resource sizing and allocation tool to develop sales force deployment strategies that added over $\$ 25$ million in annual profits compared with its base strategic plan (Lodish et al., 1988).

The German Railroad (a \$15 billion company) historically priced transportation between any two points as a simple multiple of the distance between them. However, this price structure was not competitive with driving for many potential riders. Using a large-scale conjoint analysis procedure, the company developed a BahnCard that allows customers to buy tickets at large discounts from standard per-kilometer fares. With the card, many more passengers found the train an attractive alternative to driving. With 
3.5 million cardholders, the BahnCard has increased the firm's profits by more than $\$ 200$ million/year (Dolan and Simon, 1996).

Each of these four examples involves a messy problem, a model, some data, managerial judgment, and a successful, profitable outcome for the firm. See Staelin (1999) for recent additional examples in such areas as sales promotion planning, movie scheduling, industrial product line development, and in forecasting the diffusion of High-Definition Television (HDTV). Fig. 1 is an overview of the marketing engineering approach to decision making, stressing the use of an interactive computer model to help transform objective and subjective data about the marketing environment into insights and implementation of decisions.

Although marketing engineering encompasses all the elements shown in Fig. 1, we will focus here on to transforming information and insights into decisions. The idea of using computer models to improve decision making is not new. Researchers and practitioners have long developed and implemented powerful systems that facilitate decision making in real world marketing settings (for case studies and examples, see Little, 1970; Assad et al., 1992; Lilien et al., 1992; Rangaswamy, 1993; Wierenga and van Bruggen, 1997). Yet, until recently, much of the knowledge about marketing decision models and other elements of MMSSs resided in specialized academic journals or required considerable technical expertise to use (primarily from specialized consultants). Managers and organizations have not realized the full potential of marketing knowledge and insights because of the lack of easy-to-use tools to translate knowledge into improved practice, and because the knowledge was not made available at the time decisions had to be made.

Recent advances in computer hardware, software, and network technologies now make it possible to disseminate marketing engineering tools and solutions to almost every practitioner. Hundreds of commercial software decision aids are now available (see, e.g., the directory of marketing software in Marketing News, 1998). Several trends, summarized below, favor the wider acceptance of the marketing engineering approach.

\subsection{High-powered personal computers connected to networks are everywhere}

Like other professionals, marketing managers are increasingly depending on computers to perform their jobs. A senior marketing executive told us recently, "Ten years ago in my department, we had lots of people and very little software. Today, we have lots of software and very few people." These computers are being networked with other computers through local area networks (LANs) and, in some cases, connected to external computers and databases all over the world through wide area networks (WANs), such as the Internet. In such an environment, software will be transformed into "digital networked knowledge assets." As marketing engineering is em-

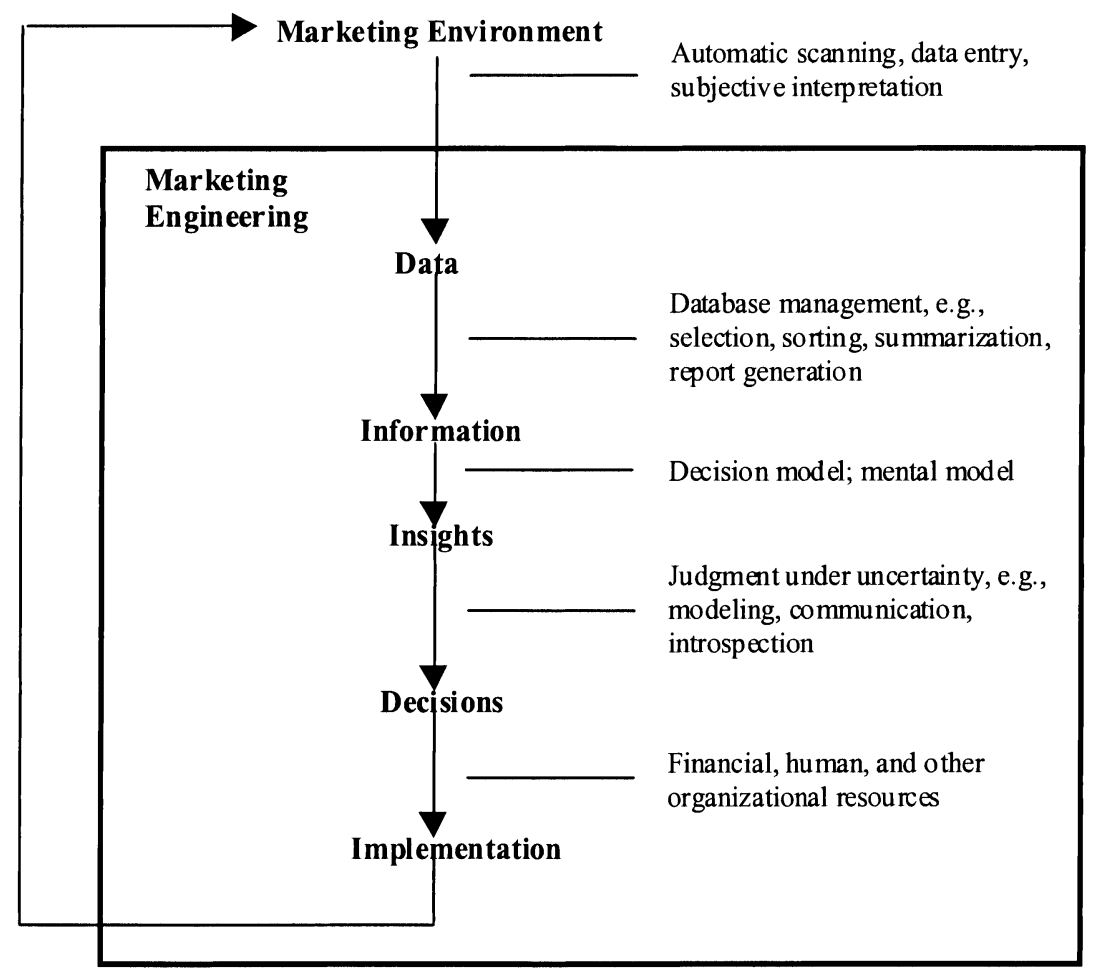

Fig. 1. The marketing engineering approach to decision making helps transform objective and subjective data about the marketing environment into decisions and decision implementations. 
bedded into more software and distributed widely, we expect an increase in the managerial ability to gather, process and share information, and to apply marketing knowledge at the point of decision making.

\subsection{The volume of data is exploding}

The automatic electronic capture of data related to transactions with customers and the growth of interactions and exchange via the Internet is generating massive amounts of potentially useful information about the preferences and behavior of customers. In a sense, abundance of data can sometimes be a bigger problem than a lack of data. For example, the amount of Point of Sales (POS) data that can be collected by means of retail checkout scanners, is enormous. Ing and Mitchell (1994) estimate that a single store could generate around 50,000 transactions/day. These transactions may involve 25,000-30,000 SKUs for a (US) supermarket and up to 1.5 million SKUs for a department store, often leading to 10-20 Gbytes of marketing data per week. It requires great managerial skills, advanced analytical capabilities, sophisticated information technology, and superior organizational capabilities to transform these data into actionable marketing knowledge. While available data have grown exponentially, the human brain has not advanced in a comparable manner to process and interpret these data (Simon, 1997). Managers need new methods and technologies, such as marketing engineering, to make decisions in data-intensive environments that overwhelm our ability to retrieve, process, and report information.

\subsection{Firms are reengineering marketing}

Today's corporate mantra seems to be "flatter organization, ad hoc teams, outsourcing, strategic relationships, and reduced cycle times." In this environment, firms are reengineering marketing functions, processes, and activities for the information age. In the reengineered firm, centralized decision making, characteristic of traditional hierarchical organizations, is giving way to decentralized decision making that is characteristic of entrepreneurial organizations. As a consequence, marketing managers are increasingly dealing directly with market information and using computers to do tasks that were once done by staff support people. Companies are also requiring marketing expenditures to be justified in the same way as other investments, and meeting similar financial hurdles. Thus, firms need to replace the work previously done by staff with other forms of support (and to justify that investment).

Marketing engineering is a way to capitalize on these trends. Clearly, markets are not controlled settings where careful observation will permit unambiguous understanding and precise actions. But neither are they so complex as to defy understanding. They fall somewhere between these two extremes. Marketing engineering enables us to capture the essence of marketing problems in well-specified models, and it improves our ability to make decisions that influence market outcomes.

\section{Marketing engineering effectiveness}

Wierenga et al. (1999) (WVS) provide a detailed review of the literature on the effectiveness of marketing engineering (MMSS in their terminology). (For purposes of this paper, we will use the terms marketing engineering and MMSS interchangeably.) They report that there is substantial evidence that MMSS can increase firm profit and other measures of performance. However, this success is not universal. Several antecedents of MMSS success emerge, such as support from top management, cognitive style and experience of the MMSS user, and fit of the MMSS with the decision environment. Often, it is not clear what people mean by success of an MMSS. Some success measures include the extent to which the MMSS was actually used by decision makers, the effect of an MMSS on market share, profit, forecast accuracy, and decision confidence, and the acceptance of the system's recommendations by management. WVS highlight five related factors that determine the success of a MMSS. These are: (1) the demand for decision support; (2) the supply of decision support (the decision support offered by the MMSS); (3) the match between demand and supply; (4) the design characteristics of the MMSS; and (5), and the characteristics of the implementation process of the MMSS. Together with the dependent variable, success of the MMSS, these factors constitute the main building blocks of the framework presented in Fig. 2 .

WVS suggest that the match between the demand side (the decision processes to be supported) and the supply side (the functionality of the management support systems employed) is the primary driver for the potential success of an MMSS. They distinguish between the potential success of an MMSS and its actual success, and posit that the extent to which success is realized depends on the design characteristics of the MMSS and the characteristics of its implementation process (see also Davis, 1989; Alavi and Joachimsthaler, 1992). Our discussion in Section 2 suggests that we are seeing favorable trends on the demand side (Box 1: shorter product life cycles, flatter organizations with distributed decision making), as well as on the supply side (Box 2: decreasing costs of computation and communication, and consequently, increasing use of computers, data, networks, and software), leading to a better match between supply and demand (Box 3). The extent and the nature of this match determine the potential success of an MMSS. However, whether or not this potential is actually realized depends on two sets of factors, design characteristics (Box 4) and implementation characteristics (Box 5). Superior system designs (Box 4) and other factors described below will favor broader implementation (Box 5) and drive the success of marketing engineering efforts. 


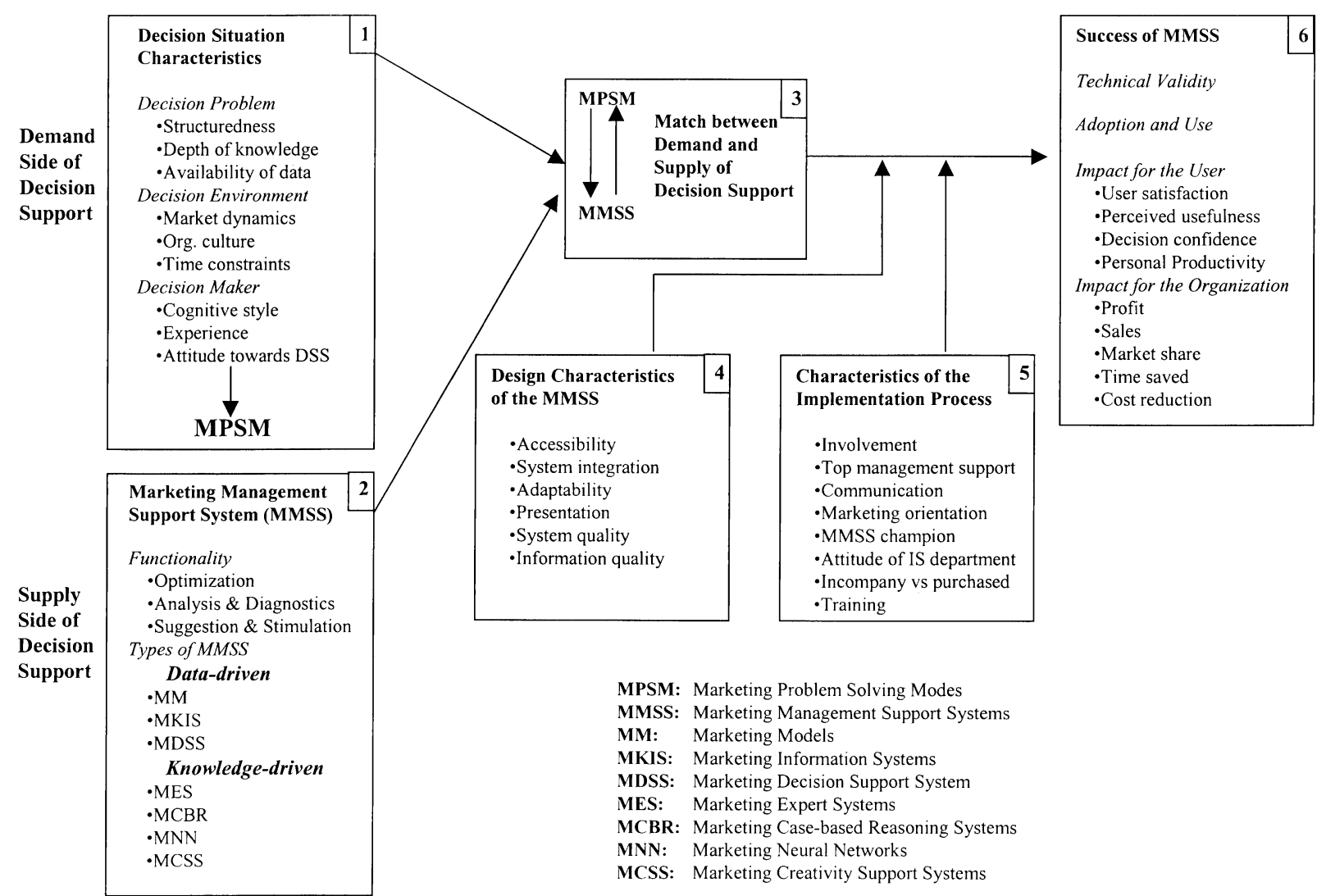

Fig. 2. Integrative framework of the factors that determine the success of a MMSS. Source: Wierenga et al. (1999).

Let us focus on some MMSS design and implementation characteristics (Boxes 3 and 4). The wide availability of spreadsheet software, such as Excel, has made it easier to work with mathematical representations of marketing phenomena. For example, marketing spreadsheets typically include planned marketing expenditures and the associated gross and net revenues. However, in most cases, the model developer does not establish a relationship, within the spreadsheet, between marketing inputs (e.g., advertising) and sales revenues. Thus, marketing inputs only impact net revenue as a cost item. We refer to such spreadsheets as "dumb" models. They make little sense as marketing models because they are silent about the nature of the relationship between marketing inputs and outputs. For the spreadsheet model to make sense, the model developer must define objectives and variables explicitly and specify the relationships between variables. In a "smart" model, an equation or "response model" will be embedded in the spreadsheet. The manager can then look at the effect of advertising on both sales and revenues to see if increases or decreases in advertising can be justified. Hence, the design environment (knowledge, software, as well as data) facilitates marketing engineering.

A factor that enhances MMSS implementation (Box 5) is the demonstration of improved decision making within the organization: How does the marketing engineering approach perform under either experimental or real decision contexts?
As a partial answer, in Fig. 3, we present summaries of studies that have evaluated the impact of models in improving prediction accuracy through improved consistency of decision making.

Consider the first row of Fig. 3 where the formalized intuition of experts captured in a simple linear model outperforms the experts themselves. Accuracy here improved from $19 \%$ correlation between direct expert judgments of student performance to $25 \%$ correlation using a linear, descriptive model relating past judgments to the data available to make those judgments. An explanation for this improvement is that the decision model more consistently applies the expertise of the experts to new cases.

The third column in Fig. 3 lists the accuracy of an "objective" linear regression model. For the academic performance study, the independent variables for the regression model were the same factors used by the experts, but the dependent variable was a known measure of the academic performance of the graduate students. The predictions in this case were based on a holdout sample of data to which the objective model was applied. For this model, the correlation of predictions with true outcomes was $54 \%$. Fig. 3 also shows the average correlations between predictions and true outcomes across several studies. We see that subjective decision models had an average correlation of $39 \%$ with true outcomes as compared to $33 \%$ for the intuitive mental models. For more details about these 


\begin{tabular}{|c|c|c|c|}
\hline $\begin{array}{l}\text { Types of judgments experts had to } \\
\text { make }\end{array}$ & $\begin{array}{l}\text { Mental } \\
\text { Model* }^{*}\end{array}$ & $\begin{array}{l}\text { Subjective } \\
\text { Decision } \\
\text { Model** }^{* *}\end{array}$ & $\begin{array}{c}\text { Objectiv } \\
\text { e } \\
\text { Decision } \\
\text { Model** }_{*}^{* *}\end{array}$ \\
\hline $\begin{array}{l}\text { Academic performance of graduate } \\
\text { students } \\
\text { Life expectancy of cancer patients } \\
\text { Changes in stock prices } \\
\text { Mental illness using personality tests } \\
\text { Grades and attitudes in psychology } \\
\text { course } \\
\text { Business failures using financial } \\
\text { ratios } \\
\text { Students' ratings of teaching } \\
\text { effectiveness } \\
\text { Performance of life insurance } \\
\text { salesman } \\
\text { IQ scores using Rorschach tests }\end{array}$ & $\begin{array}{l}.19 \\
-.01 \\
.23 \\
.28 \\
\\
.48 \\
.50 \\
.35 \\
.13 \\
.47\end{array}$ & $\begin{array}{l}.25 \\
.13 \\
.29 \\
.31 \\
\\
.56 \\
\\
.53 \\
\\
.56 \\
.14 \\
.51\end{array}$ & $\begin{array}{l}.54 \\
.35 \\
.80 \\
.46 \\
\\
.62 \\
\\
.67 \\
\\
.91 \\
\\
.43 \\
.54\end{array}$ \\
\hline $\begin{array}{l}\text { Mean (across many studies) } \\
\text { *Outcomes directly predicted by exp } \\
\text { **Subjective Decision Model: Outco } \\
\text { regression model, formalizing past } \\
\text { predictions made by experts. } \\
\text { *** Objective Decision Model: Linear }\end{array}$ & $\begin{array}{l}.33 \\
\text { ts. } \\
\text { es predic } \\
\text { odel deve }\end{array}$ & d subjective & $\begin{array}{r}.64 \\
\text { inear } \\
\text { m data. }\end{array}$ \\
\hline
\end{tabular}

Fig. 3. Degree of correlation with the true outcomes of three types of models, showing that even subjective decision models are superior to mental models, but that formal, objective models do far better. Source: Russo and Shoemaker (1989, p. 137).

studies, see Camerer (1981), Goldberg (1970) and Russo and Schoemaker (1989).

These results point to a few interesting conclusions. (1) When managers can build an objective model based on actual data, they will generally predict the best. However, in many decision situations, we do not have data that show the accuracy or the consequences of past decisions made in the same context. In such cases, the next best option is to codify the mental model decision makers use into a formal decision model. The calibration of response models using the decision calculus method (Little, 1970) is a way to formalize the mental models of decision makers. (2) Among these three types of models, the least accurate is the mental model. However, on average, all three types of models had a positive correlation with the truth, while a model with random predictions would have had zero correlation with the truth. (3) Managers should focus their attention on finding variables useful for prediction, but should use decision models to combine the variables in a consistent fashion.

The studies listed in Fig. 3 focus only on forecasting tasks. Other studies have examined performance in such managerial tasks as resource allocation and employee recruitment (Chakravarti et al., 1979; McIntyre, 1982; Gundersen et al., 1995). Although many of these studies show that the use of decision support tools generally enhances performance, this is not always the case. Indeed, some studies show that decision quality worsened as a result of using decision support tools (for a review, see Sharda et al., 1988). We need more studies to fully articulate the value of decision models, especially to identify how and why they influence the decision making process.

Managers recognize that models are incomplete, and therefore, they correctly believe that model results cannot be implemented without being modified by judgments. If model results are to be tempered by intuitive judgments, why not rely on judgments in the first place? The latter conclusion, however, does not follow from the first. As Hogarth (1987, p. 199) notes, "When driving at night with your headlights on, you do not necessarily see too well. However, turning your headlights off will not improve the situation."

Decision support tools and mental models should be used in conjunction, so that each works to strengthen the areas where the other is weak. Mental models can incorporate idiosyncratic aspects of a decision situation, but they also overfit new cases to old patterns. On the other hand, decision models are consistent and unbiased, but underweight idiosyncratic aspects. In a forecasting task, Blattberg and Hoch (1990) found that predictive accuracy can be improved by combining the forecasts generated by decision models with forecasts from mental models. Further, they reported that a 50-50 (equal weighting) combination of these two forecasts provided the highest predictive accuracy.

Marketing engineering can be both data-driven and knowledge-driven. A data-driven support tool can answer "what if" questions based on a quantified market response model (Lilien and Rangaswamy, 1998, Chap. 2). A knowledge-driven decision support tool captures the qualitative knowledge that is available about a particular domain. An example is the ADCAD expert system for advertising design (Burke et al., 1990). (Other knowledge-driven decision support technologies relevant for marketing include case-based reasoning, neural networks, and creativity support systems; see Wierenga and van Bruggen, 2000.)

There are other benefits to the marketing engineering approach. Managers using this approach could explore more decision options, consider decision options that are farther away from "base solutions" (van Bruggen et al., 1998), more precisely assess the relative impact of different mar- 
keting decision variables, facilitate group decision making, and enhance their own subjective mental models of market behavior. Despite these benefits of the marketing engineering approach, its adoption and use are far from universal at this moment. In Section 4, we will discuss possibilities for changing this situation.

\section{From promise to realization}

Several factors can foster the transition of marketing engineering from being a promising approach used by a select few to its wider adoption in managerial settings. Here, we focus on three factors: (a) end-user modeling, (b) user training, and (c) marketing engineering over the Internet.

\subsection{End-user modeling}

Marketing engineering can range from very sophisticated systems that are developed by a team of experts to those that can be quickly put together by an individual (end-user) with a basic knowledge of marketing and marketing engineering. Many large-scale marketing systems have been put together by teams of experts and such applications will continue. At the same time, the wide availability of desktop computers will encourage development and deployment of end-user systems. To be successful, end-user systems require a good fit with the abilities and preferences of the particular decision maker, direct accessibility, adaptability, and the possibility of obtaining quick answers, as many real-life marketing problems have severe time constraints. End-user systems have the following key characteristics (Powell, 1997).

1. The problem-solving process is initiated and completed by an individual who has to deal with a business problem. The user is rarely a technical analyst or a modeling specialist. The objective of the marketing engineering effort is to gain a better understanding of the specific decision problem and the alternative courses of action available to the user.

2. The modeling approach is non-mathematical in nature, although the underlying models themselves may be mathematical. The user relies on graphics, spreadsheets, and canned software to put together a marketing engineering solution to reflect his/her understanding of the business problem.

3 . The user develops the system under budget and time constraints, and it has the characteristics of a good engineering solution, namely, do as good a job as you can, cheaply, and with what you can obtain easily. The manager uses whatever information is readily available along with a healthy dose of creativity. The underlying model itself may be less thorough and scientific than models developed by academic researchers or by professional management scientists. Judgment plays a big role in generating inputs to the model and in interpreting the results.
4. The end-user system is used for generating directional insights, rather than for providing specific numerical guidelines. In contrast to full-blown decision support systems (e.g., a hotel's or an airline's yield management system), end-user models often produce outputs that are more useful for the general patterns they reveal (e.g., the feasible range of prices) than for a specific output.

Fig. 4 summarizes differences between end-user systems and high-end systems. Success with end-user systems may provide the impetus for managers to develop organization-wide implementations of marketing engineering in the form of decision support systems that are linked to corporate databases.

\subsection{User training}

As we will illustrate below, some of the big benefits from marketing engineering are being realized through end-user modeling. Indeed, two of us (Lilien and Rangaswamy) have developed an end-user tool kit that is facilitating the transfer of marketing engineering technology from academia to practice. A key element associated with the necessary training is to embrace learning by doing. The material has been adapted to advanced undergraduate programs, MBA and Executive MBA programs. Firms, such as Kodak Medical Imaging, are considering making this form of training mandatory for all marketing-related employees. Wharton's New Product Development Executive program has adopted a subset of the material (Lilien and Rangaswamy, 1999) as an analytic supplement to the more conceptual material typically taught in such programs.

A salient characteristic of the marketing engineering tool kit is that it is immediately amenable to application. Hence, managers can apply the concepts of segmentation, targeting, positioning, resource allocation, and the like to their own businesses in real time during training sessions. Managers see the potential value of such exercises because of the "anticipatory learning" about what might happen under various realistic scenarios facing them. And MBA

\begin{tabular}{|c|c|c|}
\hline & End-user Systems & High-end Systems \\
\hline Scale of problem & Small to medium & Small to large \\
\hline $\begin{array}{l}\text { Time availability } \\
\text { for setting up model }\end{array}$ & Short & Long \\
\hline Costs/benefits & Low to medium & High \\
\hline User training & Moderate to high & Low to moderate \\
\hline $\begin{array}{l}\text { Technical skills for } \\
\text { setting up model }\end{array}$ & Low to moderate & High \\
\hline Recurrence of problem & Low & Low or High* \\
\hline
\end{tabular}

Fig. 4. Two extremes of marketing decision support systems: end-user vs. high-end systems. Although the marketing engineering approach applies to both types of systems, we focus on end-user systems in this paper. Source: Adapted from Powell (1997). 
students can apply the concepts to problems that they conceptualize during the semester and successfully complete projects of real value during the course, as the following example illustrates.

\subsubsection{Case example: sales force sizing and allocation at $\mathrm{C}$-Tek}

We referred to the Syntex Laboratories case in an earlier section of this paper. The ME book and software (Lilien and Rangaswamy, 1998) includes the Syntex Laboratories case and related software to help students determine how many salespeople Syntex should hire during the following 3 years and how they should be deployed across market segments. Students also have access to video tape testimonials by Syntex management (Senior VP, Marketing and Company President) indicating that the use of the model provided \$25 million in profit above the firm's strategic plan (although they also indicated that if they had been wiser in using the model, they could have made more than twice that amount).

We applied the judgmental response model/Syntex approach to a company we will call C-Tek (disguised name), an industrial materials supplier, that was investigating the appropriate size and allocation of one of its US sales forces. The current situation was that US sales was around US $\$ 100$ million and C-Tek currently employed 78 salespeople who worked out of 14 sales branches.

We ran a 1-day judgmental response session (see Lilien and Rangaswamy, 1998, pp. 249-255 for details) with 16 senior sales representatives, national sales managers, marketing managers, and marketing research analysts. After a $1.5 \mathrm{~h}$ introduction session, we broke the group into four subgroups, each of which built a response function for three to four sales branches, essentially answering the following questions:

\begin{abstract}
"What would sales be in 3 years at this branch with: (a) No sales force representation? (b) One fewer sales representative? (c) The same number of sales representatives? (d) One more sales representative? (e) A very large increase in the number of sales representatives?"
\end{abstract}

With these and a few other model inputs (market sizes, growth rates, profit margins), we ran a number of model cases and showed that:

- Two of their (14) sales branches were significantly over-resourced while three of the others were under-resourced.

- Profits could be increased by $4 \%$ simply by reallocating representatives from over-resourced to under-resourced branches.

- Adding 25-30 representatives could make an additional profit increase of $7 \%$ (for a total of $11 \%$ ).

These results proved to be robust with respect to many sensitivity analyses we ran with respect to profit margin, response function estimates, market growth rates and the like. On the basis of this experience, the team decided to propose a major increase in sales force staffing to the board at a meeting that was scheduled 2 weeks after the modeling work was completed. The team also decided to use the approach with another related sales force that was approximately twice the size of the one they had just studied. And this entire process took place in 1.5 days.

We presented the C-Tek case to a group of MBA students after they had just run the Syntex Laboratories case to illustrate the immediate and practical value of the marketing engineering approach. Such a direct application provided great credibility and motivation to the students who are faced with understanding how to address a complex decision situation with tools that involve nonlinear optimization.

\subsection{Marketing engineering on the Internet}

We expect that the trend towards end-user systems will become more pronounced with the wider adoption of the Internet. As more managers begin to use the Internet as a resource for their day to day decision making (e.g., for getting information, communicating their decisions), it is likely that they will also be more inclined to use decision models that are accessible on the network. With the growing use of the Java and ActiveX software objects that can be distributed over the Internet, and the use of accepted standards for content display and manipulation (e.g., $\mathrm{XML}$ ), more sophisticated interactive decision models can be delivered directly over a computer network. While many of the current models available over the Internet address simple problems, such as computing amortization schedules or calculating the market value of a stock portfolio, more sophisticated models are on the horizon. Within the next few years, many sophisticated marketing models will be available on demand over the Internet, 24 h/day, 7 days/week. In fact, most of the marketing engineering tool kits in Lilien and Rangaswamy will be available on the Internet by end of year 2000, requiring nothing more than a browser to access and use them (www.mktgeng.com).

\section{Marketing engineering in perspective}

According to our assessment, marketing engineering provides demonstrable value in the field and in the laboratory. Indeed, some recent research (Lilien et al., 1999) that tested specific marketing engineering models in a laboratory situation suggests the following.

1. Marketing engineering resource allocation models improve objective market results (profit) achieved by the users, as well as their subjective perceptions, such as their satisfaction with their decisions.

2. The marketing engineering tool kit used by the subjects changed the basis of allocation decisions (e.g., shift focus to growing products, profitable products, switchable 
customers, etc.), and model users consider options that are farther away from "status quo" decision options.

To date, we have also learned some important lessons from our experiences with how managers work with marketing engineering tools. The most important ones are the following.

\subsection{End-user software allows rapid prototyping}

Markets are changing so quickly that decisions must reflect quick adaptation rather than careful optimization. Thus, to be useful, decision aids must be capable of rapid prototyping. Even when a full-blown marketing engineering project is not feasible, trying out a model on a smaller, related problem can provide managers with useful insights and document the potential opportunity cost of not doing a full-scale study.

\subsection{Software empowers}

Our experience and our experimental results suggest that managers explore more strategic options and options farther away from the "status quo" than they would consider with more traditional approaches. The software also has a favorable impact on the decision processes and learning that occur in this decision environment, especially if it provides feedback on the potential consequences of alternative actions.

\subsection{Empowerment has its downside}

The deceptive simplicity of using much of the current software and the presumed scientific credibility of the underlying models give users a false sense of security. We have observed two interesting situations: students and managers with strong quantitative backgrounds are often drawn to the technical aspects of the results and sometimes miss the big picture. Those with weak analytical skills either ignore model results and go with their intuition or accept the results uncritically. The best outcomes we have seen come from groups that include people with different levels of analytical abilities who pool their efforts while questioning and supporting one another. These groups use the model results as one input into a decision process that also includes common sense and judgment.

\subsection{Marketing engineering means better marketing}

Marketing engineering is NOT about the models and the tools. Rather, it is a systematic process for integrating marketing concepts, data, beliefs, analytical techniques, and software engineering to enhance both the process and outputs of decision making. Well-implemented marketing engineering results in improved decisions and better marketing.

\subsection{Marketing engineering demands judgment}

Models are simplified and incomplete representations of reality. Models developed to support strategic decisions (e.g., positioning) usually provide insights concerning the directional nature of actions but offer no specific guidelines, while models developed to support operational decisions offer both narrow and specific recommendations (How many sales calls should a salesperson make to a given account in the next quarter?). In using both types of models, managers must temper the model results by using their own judgment. For strategic decisions, managers must use judgment to translate broad guidelines into specific actions. For operational decisions, managers must use their judgment to finetune specific recommendations to fit with the overall strategy of the firm.

Our insights about the benefits, the process, the costs, the benefits, and the future of marketing engineering are preliminary and demand much more research than we have outlined here. Marketing engineering is not a panacea and the approach may not be appropriate for everyone or in every situation. But as we explore more carefully the research opportunities implicit in Figs. 1 and 2, we will have a better understanding of how best to use theory and technology to improve marketing practice through marketing engineering.

\section{A view of the future}

We are near the end of the era when firms could gain competitive advantage merely by having market information. Today, large firms have access to more market and customer information than they can use. More information can obscure rather than enlighten. In a project called "Dying for Information," Reuters (1996) carried out a survey among 1300 managers in the UK, USA, Australia, Singapore, and Hong Kong. They found that managers in environments where they are receiving increasing quantities of information find that environment very stressful and $49 \%$ of the managers interviewed said that they were often unable to cope. They reported ill health and deteriorating personal relationships along with other symptoms such as paralysis of analytical capacity, increased anxiety and self-doubt, and a tendency to blame others. Having too much information, without the proper systems for scanning the information and finding what is important and what can be discarded, might be just as dangerous as having too little information.

To gain the most value from information, firms are trying new approaches. (1) They are using computer and communication technologies to make relevant information available in a timely manner to their entire workforce, using techniques such as Knowledge Discovery in Databases (KDD) and data mining with neural networks and genetic algorithms. (2) They are developing new ways to 
help employees use specialized knowledge (e.g., marketing engineering) to convert information into more effective decisions and actions. Marketing engineering approaches that include firm-specific knowledge (e.g., a customized conjoint analysis model) can help firms transform market information into superior products. Such uses of information are not transparent to competitors and not likely to be replicated by them, leading to competitive advantage. Information has value only if you use it to drive decisions and actions. As Barabba and Zaltman (1991, p. 3) put it, "competitive advantage resides increasingly in how information is used rather than in who has information."

Many firms are putting together a new corporate activity called Marketing Information Systems (MKIS) to support and enhance enterprise-wide performance using marketing information. Although the concept of MKIS has existed for a number of years (see, e.g., Kotler, 1996), the scope and potential value of the present-day MKIS are far greater than was envisioned in those early days. Further, as Cox and Good (1967) long ago pointed out, organizational problems are more important than technical problems in order to make such systems successful. They stress the need for a "System-Manager Balance", a balance that must be maintained between the demand side and the supply side of MMSSs as we suggest in Fig. 2.

MKIS, typically located within the marketing department, is charged with harnessing marketing-related information and distributing and facilitating its use within the firm. Even as the marketing function seems to be in decline, the marketing concept itself appears to be gaining wider acceptance in firms (Doyle, 1995). Marketing is becoming an enterprise-wide activity, rather than the exclusive domain of a specific department. Firms see MKIS as a way to use marketing information to make everyone in the firm realize that he/she must be more responsive to customer needs and wants and to the competitive environment.

Historically, a major function of information systems has been to provide timely access to information. MKIS can now integrate end-user decision models with traditional information systems to enhance the firm's ability to use marketing engineering. At least six current trends favor this integration of information. Firms are (1) investing in the infrastructure they need to develop and maintain extensive corporate databases (data warehouses) and are implementing Enterprise Resource Planning systems; (2) using online analytical processing (OLAP) to integrate modeling capabilities with databases; (3) deploying intelligent systems to automate some modeling tasks; (4) developing computer simulations for decision training and for exploring multiple options; (5) installing groupware systems, such as Lotus Notes, to support group decision making; and (6) enhancing user interfaces to make it easier to deploy even complex models more widely.

Glazer (1991) has tried to predict what might occur in the next decade or so because of the increasing availability of information and the decreasing cost of processing that information; he expects (a) shorter and less predictable product life cycles; (b) a shift in power from sellers to buyers; (c) more focus on product profitability and less on share; (d) more (and less formal) alliances; (e) more focus on cooperation and less on competition; and (f) greater reliance on decision teams whose members simultaneously process shared information.

We have seen all of these changes occurring and they demand rapid and coherent marketing decisions supported by the marketing engineering approach. Shorter product life cycles means that analysis has to be both quick and sound. Increased buyer power (e.g., through use of electronic buying agents (West et al., 1999)) means that companies must better understand buyer values to succeed in the market. An emphasis on profitability means that marketers must focus on setting objectives. Alliances and cooperation mean that we need newer models to support these multiple decision makers. And the increase in team decisions means that groupware will increase in importance.

These trends will drive the marketing engineering imperative. Increasingly, we will be relying on marketing engineering approaches, perhaps those available on the Internet, so that better-informed, disciplined marketing decisions can be made anywhere, anytime by anyone.

While the marketing function in companies may decline in importance in the years to come, marketing can only increase in importance. Years ago, Peter Drucker noted that marketing is too important to be left to marketers; that statement is even more true today. Likewise, marketing tools viewed as digital networked knowledge assets are too important to be left to software programmers. Indeed, these factors underscore the need for a dedicated program of research on marketing engineering. While Wierenga and van Bruggen $(1997,2000)$ have laid out a framework that suggests why and when the approach has value, we need a better understanding of how to apply such a framework (e.g., Fig. 2) to specific marketing problems. The challenge, to use a medical analogy, is to develop the detailed set of clinical trials that demonstrate when, how, and why marketing engineering works and what can be done to improve its effectiveness while minimizing the risk of organizational harm.

Marketing engineering links marketing theory to marketing practice. In marketing, practice without theory teaches little, while theory without practice means even less. In the same vein, software designed without embedding marketing concepts and theories, or marketing concepts with no foreseeable software implementations, will be of little use to practitioners. Today's practicing managers - pressured to understand and operate in complex and risky markets increasingly depend on the concepts and tools of marketing engineering which serve as a channel through which the insights and knowledge produced by marketing scientists can be distributed to practice. For example, the executives we teach invariably try out software using some of their own 
data and immediately see the relevance and the benefit of the marketing engineering approach. The pressure for academics to show greater relevance for their work is increasing academic interest in marketing engineering as well. These two pressures point to a marriage of convenience that should lead to improved tools for practitioners and interesting research problems for academics. As with all successful partnerships, both stand to gain.

\section{References}

Alavi M, Joachimsthaler EA. Revisiting DSS implementation research: a meta-analysis of the literature and suggestions for researchers. Manage Inf Syst Q 1992;16(1):95-116.

Assad AA, Wasil EA, Lilien GL, editors. Excellence in management science practice. Englewood Cliffs, NJ: Prentice-Hall, 1992.

Barabba VP, Zaltman G. Hearing the voice of the market: competitive advantage through creative use of market information. Boston, MA: Harvard Business School Press, 1991.

Bazerman MH. Judgment in managerial decision making. New York: Wiley, 1998.

Blattberg RC, Hoch SJ. Database models and managerial intuition: 50 percent model and 50 percent manager. Manage Sci 1990;36(8): 887-99 (August).

Bucklin RE, Lehman DR, Little JDC. From decision support to decision automation: a 2020 vision. Mark Lett 1998;9(3):235-46.

Burke RR, Rangaswamy A, Wind J, Eliashberg J. A knowledge-based system for advertising design. Mark Sci 1990;9(3):212-29.

Camerer C. General conditions for the success of bootstrapping models. Organ Behav Hum Perform 1981;27(3):411-22.

Chakravarti D, Mitchell A, Staelin R. Judgment based marketing decision models: an experimental investigation of the decision calculus approach. Manage Sci 1979;25(3):251-63 (March).

Cox DF, Good RE. How to build a marketing information system. Harvard Bus Rev 1967;45(3):145-54 (May/June).

Davis FD. Perceived usefulness, perceived ease of use and user acceptance of information technology. Manage Inf Syst Q 1989;3(1):60-95.

Dolan RJ, Simon H. Power pricing. New York: The Free Press, 1996.

Doyle P. Marketing in the new millennium. Eur J Mark 1995;29(13):23-41.

Gensch DH, Aversa N, Moore SP. A choice modeling market information system that enabled ABB Electric to expand its market share. Interfaces 1990;20(1):6-25 (January-February).

Glazer R. Marketing in an information intensive environment: strategic implications of knowledge as an asset. J Mark 1991;55:1-9 (October).

Goldberg LR. Man versus model of man: a rationale, plus some evidence for a method of improving on clinical inferences. Psychol Bull 1970;73(6):422-32.

Gundersen DE, Davis DL, Davis DF. Can DSS technology improve group decision performance for end-users? An experimental study. J End-User Comput 1995;7(2):3-10 (Spring).

Hogarth RM. Judgment and choice. 2nd ed. New York: Wiley, 1987.

Ing D, Mitchell AA. Point-of-sales data in consumer goods marketing: transforming the art of marketing into the science of marketing. In: Blattberg RC, Glazer R, Little JDC, editors. The marketing information revolution. Boston, MA: Harvard Business School Press, 1994. pp. $30-57$.
Kotler P. A design for the firm's marketing nerve center. Bus Horiz 1996;9:63-74 (Fall)

Lilien GL, Kotler P, Moorthy KS. Marketing models. Englewood Cliffs, NJ: Prentice-Hall, 1992.

Lilien GL, Rangaswamy A. Marketing engineering: computer-assisted marketing analysis and planning reading. Reading, MA: AddisonWesley, 1998.

Lilien GL, Rangaswamy A. New product and brand management: marketing engineering applications reading. Reading, MA: Addison-Wesley, 1999.

Lilien GL, Rangaswamy A, Starke K, van Bruggen GH. An experimental study of the effects of DSS on marketing resource allocation decisions. Working Paper, Smeal College of Business Administration, Penn State University, University Park, PA 16802, 1999.

Little JDC. Models and managers: the concept of a decision calculus. Manage Sci 1970;16(8):B466-85 (April).

Lodish LM, Curtis E, Ness M, Simpson MK. Sales force sizing and deployment using a decision calculus model at Syntex Laboratories. Interfaces 1988;18(1):5-20 (January-February).

Marketing News. Directory of software for marketing and marketing research. Chicago: AMA, April 13, 2001.

McIntyre SH. An experimental study of the impact of judgment-based marketing models. Manage Sci 1982;28(1):17-33 (January).

Powell SG. From intelligent consumer to active modeler: two MBA success stories. Working Paper, Amos Tuck School of Business Administration, Dartmouth College, Hanover, NH, 1997.

Rangaswamy A. From linear programs to knowledge-based systems. In: Eliasberg J, Lilien GL, editors. Handbooks of MS/OR in Marketing. The Netherlands: North Holland: Elsevier Science Publisher BV, 1993. pp. $733-71$.

Reuters. Dying for information. Reuters Bus Inf, 1996.

Russo JE, Schoemaker PJH. Decision traps. New York: Doubleday and Company, 1989. pp. 132-7.

Schmitz JD, Armstrong GD, Little JDC. Cover story: automated news finding in marketing. In: Bolino L, editor. DSS transactions. Providence, RI: TIMS College on Information Systems, 1990. pp. 46-54.

Sharda R, Barr SH, McDonnell JC. Decision support system effectiveness: a review and empirical test. Manage Sci 1988;34(2):139-59 (February).

Simon HA. Administrative behavior, a study of decision-making processes in administrative organizations 4th ed. New York: The Free Press, 1997.

Staelin R, editor. Special issue on managerial decision making. Mark Sci 1999;18(3).

Tversky A, Kahneman D. Judgment under uncertainty: heuristics and biases. Science Marketing Science 1974;185:1124-31.

van Bruggen GH, Smidts A, Wierenga B. Improving decision making by means of a marketing decision support system. Manage Sci 1998;44:645-58 (May).

West PM, Ariely D, Bellman E, Huber J, Johnson E, Kahn B, Little J, Schkade D. Agents to the rescue? Mark Lett 1999;10(3):285-300.

Wierenga B, van Bruggen GH. The integration of marketing problem-solving modes and marketing management support systems. J Mark 1997;61:21-37 (July).

Wierenga B, van Bruggen GH. Marketing management support systems: principles, tools and implementation. Boston, MA: Kluwer Academic Publishing, 2000.

Wierenga B, van Bruggen GH, Staelin R. The success of marketing management support systems. Mark Sci 1999;18(3):196-207.

Wind J, Green PE, Shifflet D, Scarbrough M. Courtyard by Marriott: designing a hotel facility with consumer-based marketing models. Interfaces 1989;19(1):25-47 (January-February). 